\title{
Evaluating alternative river management options in the tidal Ouse, UK
}

\author{
T. Wang \\ Environment Department, University of York, UK
}

\begin{abstract}
The River Ouse forms a significant part of the Humber river system, providing the largest UK fresh water source to the North Sea and a valuable habitat for fish. It suffers from dissolved oxygen sag over summer months, especially downstream of industrial effluent discharges at Selby. The Environment Agency (EA) therefore proposed implementing stricter environmental limits for industries and sewage treatment works. The effectiveness of other management options is evaluated through a one-dimensional water quality model, QUESTS1D. Significant improvements in water quality from alternative options are predicted by simulation using QEUSTS1D, in comparison to tightening effluent consents. The Transfer Coefficients Matrix of $\mathrm{BOD}_{5}$ is derived in this paper to indicate the relative impacts on water quality of using different discharge locations. An integrated river policy taking into account both effluent discharges and water abstraction on the basis of their effects suggests a combined water management framework could be applied to ensure the required water quality.
\end{abstract}

Keywords: water quality modelling, effluent discharges, water abstraction, QUESTS1D, transfer coefficients matrix, integrated river policy.

\section{Introduction}

The tidal section of the Humber system forms a significant part of the Humber drainage basin, which is the largest catchment in England, draining one fifth of the land are of England [1, 2]. The sea spurn of the Humber makes the biggest freshwater contribution to the North Sea from the UK, approximately $250 \mathrm{~m}^{3} / \mathrm{s}$ [3]. The tidal Ouse is an upper section of the tidal Humber system, stretching from Naburn to Trent fall where it meets the tidal Trent; it includes four 
tributaries, the Wharfe, Derwent, Aire and Don (Figure 1). The water quality in the tidal Trent has steadily improved over the last three decades [1]. However, the tidal Ouse remains one of the worst river reaches in the tidal section of the Humber system. One impact of the poor water quality in the tidal Ouse during the warm summer months is the regular occurrence of dissolved oxygen (DO) sag, a common phenomenon of estuaries. When the flow is low, the suspended sediments (SS) move upstream and stay long enough around Selby to cause the DO sag. Other factors contribute to the DO sag in estuaries, including effluent discharges from industries and Sewage Treatment Works (STW), water abstraction, high water temperature in summer and biomass of photosynthetic plankton. The impact of SS on water quality in the tidal Ouse has not been investigated in depth, though some research has been carried out $[4,5]$.

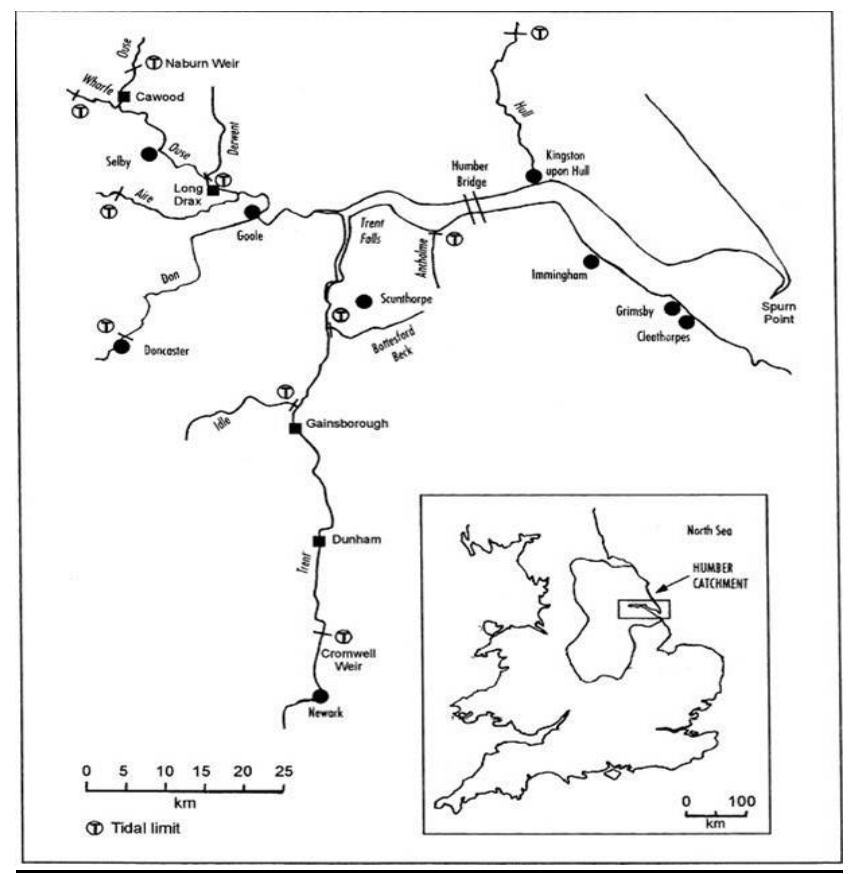

Figure 1: The tidal section of Ouse, Trent and Humber with main tributaries and monitoring sites National River Authority [3].

As a result of the DO sag, water quality in the tidal Ouse is too low to support return of spawning salmon, an important indicator of ecological health of an estuarine river. The most severe DO sag in the summer therefore persists in the upper reaches of the river between the EA monitoring sites at Selby and Long Drax. The EA proposed tightening effluent discharge consents to improve water quality. However, many other factors influencing water quality should be considered. The water in the tidal Ouse is also heavily influenced by the Aire and Don, draining from major centres of population and industry, such as Leeds, 
Doncaster and Sheffield. Their confluences to the Ouse are near the DO sag area. Rainfall also varies over space and time in the region, with highest rainfall over $1600 \mathrm{~mm}$ in parts of the Pennines due to the prevailing wind [6] and much less rainfall in the Southeast of the catchment and in summer. The inland penetration of tide at low flow transports sediment upstream and resuspends it in the water, resulting in considerable DO consumption. Much river water is abstracted by Yorkshire Water to supply portable water for over 3.5 million people, and returned to the river through STWs, reducing clean freshwater flows in northern rivers and increasing volumes of poor quality water returned from the industrial south tributaries [1].

The industries in Selby have invested substantially in controlling their effluent discharges as consents tightened. The STWs are currently improving their sewage treatment abilities to meet the requirements of Urban Waste Water Treatment Directive (UWWTD), particularly in the Don and Aire tributaries, whereas water abstraction in the Ouse and its tributaries has not been regulated to tackle the DO sag.

The research aims to evaluate alternative options to improve water quality, based on the variation of assimilative capacity of the river water using simulation of the QUESTS. More effective options for improving the water quality were outlined in the paper as implications to river policy decision in the future. A Transfer Coefficient Matrix (TCM), as a result of the analysis, is constructed, which depicts the overall distribution of assimilative capacity in the river.

\section{The QUESTS model}

\subsection{Structure of QUESTS1D model}

The original objective of the WRc QUESTS1D model was to provide a calibrated, time-dependent, one-dimensional water quality model of the Humber estuary to the National Rivers Authority (NRA) in the Anglian, Seven Trent and Yorkshire regions [7] to aid the establishment of discharge consents. It is still utilized by the EA for this purpose. The model also provides a predictive tool for evaluating the impact of pollution loads and potential pollution control options.

QUESTS1D model a one-dimensional representation of the tidal river system from tidal limits of the Ouse, Wharfe, Aire, Don and Trent to the sea spurn. It is made up of several linked programs. The Wharfe, Aire and Don in QUESTS1D stretch from their confluences with the Ouse to the tidal limits, distances of 69.9, 48.9 and $45.7 \mathrm{~km}$ respectively. The rivers Derwent and Hull are treated as point source due to their low volume and short tidal sections. The total length of the system represented is around $313 \mathrm{~km}$, with $62.5 \mathrm{~km}$ in the Ouse, $84.8 \mathrm{~km}$ in the Trent and $62.2 \mathrm{~km}$ from their confluence downstream towards the sea, divided into 282 cells.

Two models are combined into QUESTS1D; the hydrodynamic model predicts variables such as river level and water velocity and the water quality model, based on the conservation of mass, uses the results from the hydrodynamic model to incorporate the processes of advection, diffusion, decay 
and the interactions between the substances in the river water. Values of DO, BOD, SS, ammonia, phosphate and metals in each cell are simulated in the water quality model as well as temperature and salinity. At the time of construction, there were approximately 216 discharges to the river, with 58 major inputs in the model in 1993 [7]. The QUESTS1D model utilized in this research has 56 inputs.

\subsection{Calibrations and validation of QUESTS1D model}

The hydrodynamic model was calibrated against data from a neap tide between $15^{\text {th }}$ and $19^{\text {th }}$ May 1978 and from a spring tide between $19^{\text {th }}$ and $23^{\text {rd }}$ June 1978 , and from October 1967 and March 1968 respectively for the Don and Wharfe due to insufficient data [8]. The water quality model, was calibrated against data from a previous study by the Humber Estuary Committee [9]. This dataset comes from intensive surveys during May and June 1978 for the pollution loads inputs and water quality within the estuary. Questions concerning the modelled processes resulted in a further modification in 1994 against continuous monitoring data from 1992. Good agreement for DO in the lower Ouse could be achieved as long as the simulated bed sediment was sufficient to provide a realistic level of SS throughout the run-time. This implied the significant impact of SS on the DO concentration, as in other research $[10,11]$.

Although further work on QUESTS1D model are required to improve how it handles sediment dynamics and oxygen demand, validation against continuous monitoring data for spring and summer in 1995 and 1996 produced satisfactory results. The most recent validation against continuous monitoring data using the 1999 data displayed good agreement [12]. QUESTS1D therefore was considered suitable for water quality simulation in the Humber system, and for evaluating potential pollution controls.

\section{Results with the QUESTS model}

During this research, only 5\%ile DO saturation was assessed, although more measurements are required to satisfy compliance to regulation. DO saturation is a key indicator of water quality and of the health of aqueous habitats [13]. It is also the key constraint on many transformations of constituents in the water and thus significantly influences the concentrations of other constituents. Here compliance of DO saturation was evaluated against a DO minimum of $30 \%$ at $5 \%$ ile value adopted by the EA to allow the return of Salmon during the summer; and any improvement in the 5\%ile DO \% was evaluated through a composite score of the Estuarine Working Party Classification Scheme (EWPCS), which illustrates the DO\% throughout the tidal Ouse/Humber reach, particularly in the area of DO sag.

From 1995 to 2003, the least flow occurred in 1996. However, the DO sag was most severe in the summer of 1995. This is due to unusual flow distribution in 1995, when most of the flow was in the first few months followed by a severe summer drought [5]. In this research, 1995, 1997 and 2001 are regarded as typical dry, moderate and wet years. 


\subsection{Location effects}

Figure 2 indicates the impacts on $\mathrm{DO} \%$ of relocating effluent discharges from the four major industries in Selby, compared with the original location. The negative distances are the distances of the locations upstream to the Ouse Trent confluence. All the DO\% are 5\%ile value of the simulation results.

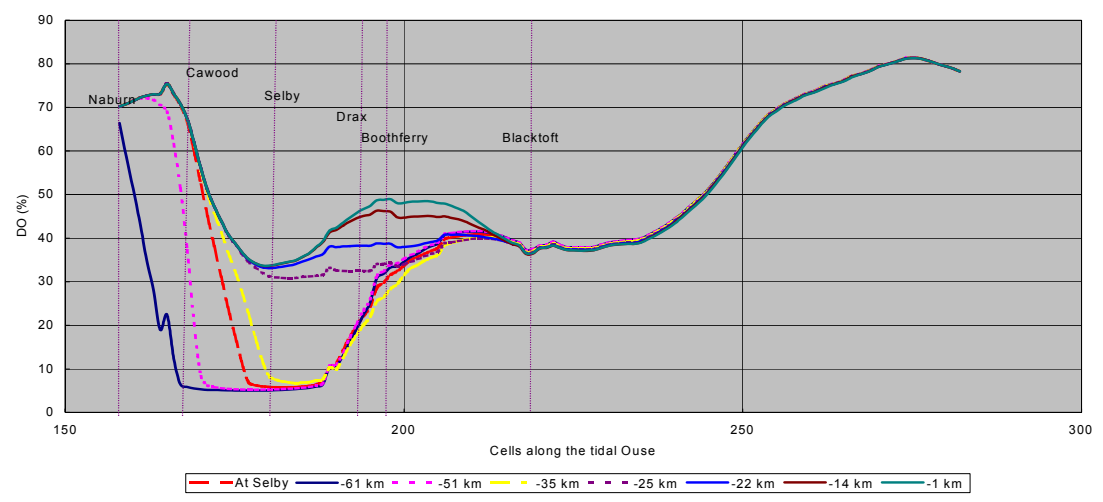

Figure 2: $\quad$ Location effects of effluent discharges on DO saturation in 1995.

Water quality improves as the location of effluent discharges moves downstream towards the confluence of the Ouse and Trent. In 1995, there was a significant DO sag between Selby and Drax when effluents were discharged anywhere beyond Selby. However, the minimum of 30\% DO\% throughout the river could be just achieved if the effluents were discharged $25 \mathrm{~km}$ upstream from the confluence, with a dramatic improvement over $35 \mathrm{~km}$. With effluent discharges further downstream, the DO sag in 1995 could have been effectively dispelled from the tidal Ouse. In the simulation for 1997, there is no obvious improvement as the discharge location moves downstream, probably due to the good water quality in general. As expected, the location effects are more obvious in the year with poor water quality, and decrease as water quality improves. Generally, the improvement in DO\% is usually slow in the upper river before Selby and the lower region after Boothferry Bridge, with the fastest improvement between these sites.

The EWPCS scores for the estuary for various discharge locations are indicated in Table 1. The monotonic water quality improvement as effluent discharge moves downstream from $\mathrm{A}$ to $\mathrm{H}$ is represented by the increasing composite scores in these two years. The two columns to the right indicate how fast the $\mathrm{DO} \%$ is improving along the river, in terms of changes in composite score for each kilometre downstream towards the next discharge point.

Indicated as the highlighted area, the discharge locations between points $\mathrm{C}$ and $\mathrm{F}$ have the highest rate of improvement in $\mathrm{DO} \%$ for each $\mathrm{km}$ moved downstream, as highlighted in the box. The diminishing rate of improvement after point $\mathrm{F}$ indicates a significant assimilative ability of the lower river, as the 
effluent removal has less impacts on DO\%. Therefore, the highest rate of change in water quality in nature reflects the locations least resistant to the effluent discharge, which are 22.5 and $27.0 \mathrm{~km}$ respectively for 1995 and 1997. This illustrates that the most sensitive area to the pollutant discharges was lower in 1995 than in 1997, which echoes the poor water quality in 1995.

Table 1: $\quad$ EWPCS Score of different discharge locations.

\begin{tabular}{|c|c|c|c|c|c|}
\hline Point & Distance & 1995 & 1997 & \multicolumn{2}{|c|}{$\begin{array}{c}\text { Improvement over each km } \\
\text { downstream in between }\end{array}$} \\
\hline A & -61 & 694 & 825 & 1995 & 1997 \\
\hline B & -51 & 753 & 866 & 5.90 & 4.10 \\
\hline C & -41 & 791 & 903 & 3.80 & 3.70 \\
\hline D & -35 & 801 & 926 & 1.67 & 3.83 \\
\hline E & -25 & 869 & 940 & 6.80 & 1.40 \\
\hline F & -22 & 876 & 949 & 2.33 & 3.00 \\
\hline G & -13 & 894 & 958 & 2.00 & 1.00 \\
\hline H & -1 & 894 & 958 & 0.00 & 0.00 \\
\hline
\end{tabular}

\subsection{Changes in the timing of discharge over the year}

Since the DO sag is greatest during the summer at low water flow, shifting the effluent discharges from summer to winter showed alleviation of DO. This first scenario is to store the effluents in June, July and August and double the effluent discharges during December, January and February, which store at least $25 \%$ of annual effluents. The second is to only discharge during the winter, $75 \%$ annual effluents being stored over the other nine months.

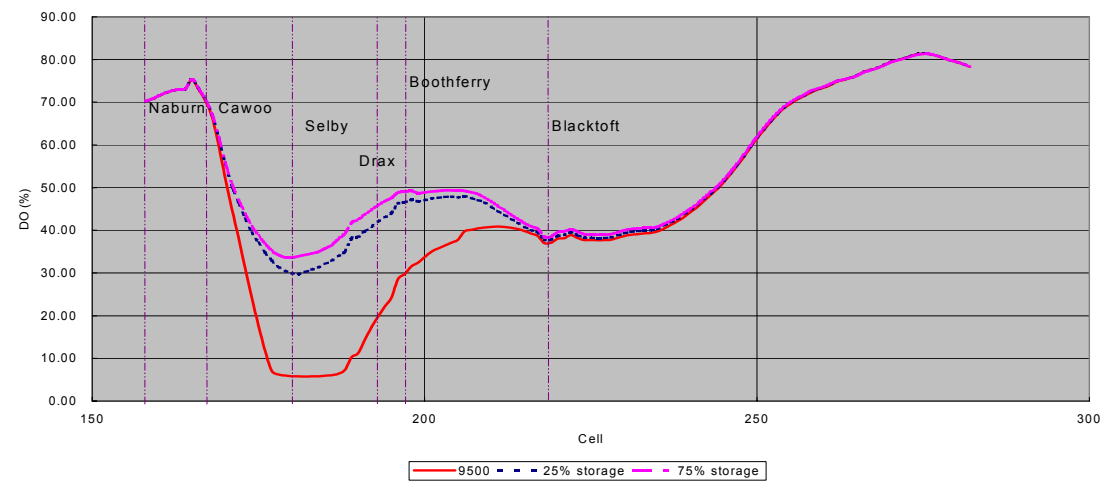

Figure 3: Effects of changing discharge timing on DO\% at 5\%ile in 1995.

Storage of $25 \%$ annual effluents would barely elevate the DO sag above the $30 \%$ minimum prescribed by the EA in 1995 as indicated by Figure 3. In 1997, $25 \%$ storage could lead to a significant improvement to eliminate the DO sag 
between Selby and Drax and keep DO\% above 40\%, since the water quality was much better than the 1995 and 1996. However, the shifting of effluent discharges would hardly make any change in the DO\% in 2002, because the effluent discharge in summer could not make a big impact due to the high summer flow in 2002 and the stricter effluent discharge consents. Storing $75 \%$ of annual effluent could only result in small $\mathrm{DO} \%$ improvement at a much higher cost; hence it is unnecessary to control the effluent in spring and autumn. Table 2 indicates the changes in the EWPCS composite score in several years.

Table 2: $\quad$ EWPCS scores of effluent discharge shifting over the year.

\begin{tabular}{|c|c|c|c|c|c|c|}
\hline Scenario & 1995 & 1996 & 1997 & 2000 & 2001 & 2002 \\
\hline Continuous & 791 & 804 & 903 & 954 & 899 & 1010 \\
\hline $25 \%$ Storage & 892 & 890 & 950 & 1042 & 964 & 1038 \\
\hline Improve & 101 & 86 & 47 & 88 & 65 & 28 \\
\hline $75 \%$ Storage & 905 & 906 & 962 & 1050 & 1003 & 1038 \\
\hline Improve & 13 & 16 & 12 & 8 & 39 & 0 \\
\hline
\end{tabular}

\subsection{Changes of effluent discharge levels}

Figure 4 indicates the impact of changes of effluent discharge levels on the DO\% in 1995. The change was expected to represent the impacts at low flow.

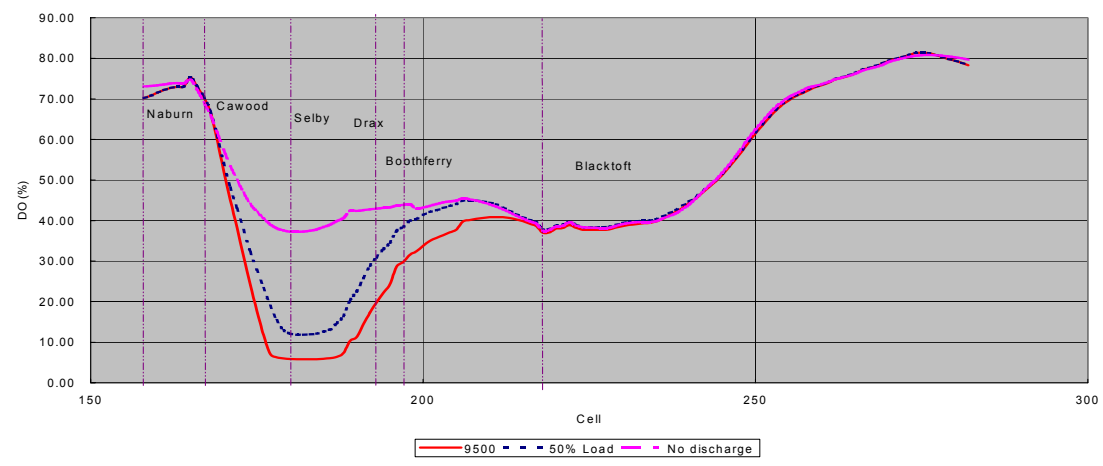

Figure 4: Effects of effluent discharges on DO\% at 5\%ile in 1995.

The DO\% profiles indicate significant improvement in 1995. However, up to $50 \%$ of effluent reduction in Selby could only result in a slight improvement in 1995 , since the $50 \%$ effluents from Selby were already strong enough to suppress DO\% down to just above $10 \%$ during the exceptionally dry summer. Only at no effluent discharge from the Selby plants would the DO $\%$ exceed the $30 \%$ minimum target. The large difference between the 50\% and $100 \%$ effluent reductions reflects a quick declining curve for $\mathrm{DO} \%$ with respect to effluent 
discharges. On the other hand, it also illustrates that in a dry year such as 1995 , the reduction of effluent discharge should and could not be considered as an effective option to tackle the DO sag.

The situation in 1997 was different due to the higher flow in summer, with almost equivalent improvement between the two scenarios. Effluent reduction as an option to increase DO\% would be reasonable in 1997. Table 3 displays the changes of EWPSC composite score in 1995 (dry), 1997 (moderate) and 2001 (wet), from $0 \%$ to $150 \%$ of original effluent. In 2001 , increasing the effluent by $50 \%$ would only result in 4 points decrease in composite score, showing a prominent assimilative capacity of the river water in rich-rainfall years.

Table 3: $\quad$ Effects on river water quality of various effluent levels.

\begin{tabular}{|c|c|c|c|}
\hline Load & 1995 & 1997 & 2001 \\
\hline $0 \%$ & 903 & 970 & 962 \\
\hline $50 \%$ & 856 & 931 & 932 \\
\hline $90 \%$ & 800 & 915 & 907 \\
\hline $100 \%$ & 791 & 903 & 899 \\
\hline $110 \%$ & 784 & 901 & 899 \\
\hline $150 \%$ & 754 & 874 & 895 \\
\hline
\end{tabular}

\subsection{Abstraction effect}

In the tidal Ouse, water was mainly abstracted for supply beyond the tidal limit of the Ouse and Derwent. As "negative pollution" [14], the effect of water abstraction return was evaluated. The water returned to the Derwent has higher impact on water quality than return to the Ouse. But neither of them is generally effective as a river management option, especially during the dry year.

\subsection{Transfer Coefficients Matrix (TCM)}

Combination of the analyses of location effects and effluent discharge levels sheds light onto the transfer coefficients matrix. TCM is a matrix of transfer coefficients within which each indicates how the concentration of pollutant has changed after discharge between any two points along the river. Therefore the TCM indicates the assimilative ability of the river water between any two points. TCM in this research was calculated based on ambient $\mathrm{BOD}_{5}$ concentration means resulting from the effluent discharges of Selby industries. Comparison of the ambient $\mathrm{BOD}_{5}$ concentration at any two locations along the river tells how much $\mathrm{BOD}_{5}$ is degraded via assimilation processes between the two points. Table 4 indicates the TCM for eight discharge locations $\mathrm{A}$ to $\mathrm{H}$ and six water monitoring sites.

Transfer coefficient values range from 0 to 1 , where 1 means there is no $\mathrm{BOD}_{5}$ degraded between these two points and 0 means there is no direct effect on the local $\mathrm{BOD}_{5}$ concentration from $\mathrm{BOD}_{5}$ increase at the effluent discharge 
location. TCM values for 1997 and 2001 were constructed similarly. The transfer coefficient does not vary much among these three years. The relatively stable value suggests that it is probably dominated by the kinetics of assimilative processes, geographical structure, water surface area, tributary positions and other factors that are generally consistent over time. An averaged TCM of these three examples would be more practically convenient for planning purpose.

Table 4: $\quad$ Transfer coefficients matrix for BOD5 discharge in 1995.

\begin{tabular}{|c|c|c|c|c|c|c|c|}
\hline Point & Distance & Naburn & Cawood & Selby & Drax & Boothferry & Blacktoft \\
\hline A & -61 & 0.17 & 0.57 & 0.39 & 0.11 & 0.07 & 0.02 \\
\hline B & -51 & 0.00 & 0.53 & 0.83 & 0.32 & 0.21 & 0.05 \\
\hline C & -41 & 0.00 & 0.01 & 0.97 & 0.53 & 0.35 & 0.07 \\
\hline D & -35 & 0.00 & 0.00 & 0.62 & 0.82 & 0.63 & 0.08 \\
\hline E & -25 & 0.00 & 0.00 & 0.06 & 0.74 & 0.89 & 0.22 \\
\hline F & -22 & 0.00 & 0.00 & 0.01 & 0.46 & 0.73 & 0.32 \\
\hline G & -13 & 0.00 & 0.00 & 0.00 & 0.09 & 0.26 & 0.62 \\
\hline H & -1 & 0.00 & 0.00 & 0.00 & 0.07 & 0.07 & 0.78 \\
\hline
\end{tabular}

\section{Concluding remarks}

Analyses of the simulation results from QUESTS1D provided a useful insight on the effectiveness of alternative water management options aiming at improving water quality, particularly to tackle the DO sag during the summer in the tidal Ouse. The results proved that the effluent discharge at Selby does relate to the DO sag downstream, especially during dry years. However, as a tidal river system, there are also remarkable influences from resuspended sediments and their landward transport with tide as well as the inputs from STWs and tributaries draining from high population areas. The sediments move up the river system during the low flow period and remain around Selby long enough to cause the observed DO sag in summer [15]. The effluent discharge from Selby exacerbates the situation when flow is low but should not be regarded as the only cause. Therefore, reduction of the effluent discharges in the Selby plants may not always be effective for tackling the DO sag, though it is regarded as the only option by the EA under most circumstances.

Location choice for effluent discharge could dramatically change DO\% in the tidal Ouse, in both dry and wet years. Shifting effluent discharges into winter also leads to significant improvement on the DO sag, since the worst DO\% usually happens in warm, low flow conditions. In most situations, $25 \%$ annual effluent storage would be enough to meet the EA's target of $30 \%$ minimum DO $\%$ at 5\% ile. These options deserve more consideration as effective management to improve the water quality and tackle the DO sag issue. They are not exclusive; hence the best option of river water management could be a combination of them or variations on them. The TCM is an important reference for river management, which could serve as a useful predictive tool for the environmental authority to evaluate the effects of river policy. 


\section{References}

[1] Edwards, A.M.C., Freestone, R.J. \& Crockett, C.P., River management in the Humber catchment. Science of The Total Environment, 194-195: pp. 235-246, 1997.

[2] Jarvie, H.P., Neal, C. \& Robson, A.J., The geography of the Humber catchment. Science of The Total Environment, 194-195: pp. 87-99, 1997.

[3] National Rivers Authority, N.R., The quality of the Humber Estuary (1980-1990), in Water Quality Series number 12, pp. 108, 1993.

[4] Freestone, R., Water Quality in the tidal Ouse, Environment Agency, 2003.

[5] Tappin, A.D., Harris, J.R.W. \& Uncles, R.J., The fluxes and transformations of suspended particles, carbon and nitrogen in the Humber estuarine system (UK) from 1994 to 1996: results from an integrated observation and modelling study. Science of The Total Environment, 314-316: pp. 665-713, 2003.

[6] Law, M., Wass, P. \& Grimshaw, D., The hydrology of the Humber catchment. Science of The Total Environment, 194-195: pp. 119-128, 1997.

[7] Slade, S. \& Morgan, N.H., Humber Estuary Water Quality Model - Phase 1 water quality model, in WRc Report CO 3472. 1993a.

[8] Slade, S. \& Morgan, N.H., Humber estuary system water quality model Phase 1 hydrodynamic model, in WRc Report CO 3327. $1993 \mathrm{~b}$.

[9] Humber Estuary Committee, The Quality of the Humber Estuary, 1961 1981, Gameson, A.L.H., (ed), Yorkshire Water Authority, 1982.

[10] Parr, L.B. \& Mason, C.F., Causes of low oxygen in a lowland, regulated eutrophic river in Eastern England. Science of The Total Environment, 321(1-3): pp. 273-286, 2004.

[11] Hanley, N., Faichney, R., Munro, A. \& Shortle, J.S., Economic and environmental modelling for pollution control in an estuary. Journal of Environmental Management, 52(3): pp. 211-225, 1998.

[12] Freestone, R., QUESTS1D Water Quality Model of the Humber System 1999 Validation, Environment Agency, 2001.

[13] Freestone, R., Tidal Ouse - Water Quality Modelling, Environment Agency, 2002.

[14] Sheail, J., The institutional development of river management in Yorkshire. Science of The Total Environment, 194-195: pp. 225-234, 1997.

[15] Cashman, A., Hardy, T., Jones, G. \& Perrings, C., Dissolved Oxygen in the Ouse: Cost Effective Solutions, Environment Department, University of York; Environment Agency, 1999. 